Management of premenstrual syndrome

\title{
Nick Panay
}

\section{Introduction}

The diagnosis and management of premenstrual syndrome (PMS) are reviewed, in particular, the evidence for pharmacological and non-pharmacological treatments. Additionally, this review takes a wider view of the situation with particular emphasis on recent attempts to achieve a global consensus on definitions and management. The development of a consensus and guidelines on the definition and management of PMS is essential to encourage acceptance of this condition by patients, health professionals and regulatory authorities.

\section{Methodology}

The Royal College of Obstetricians and Gynaecologists (RCOG) Green-top Guideline No. 48 on Management of Premenstrual Syndrome ${ }^{1}$ was used as the starting point for this review. The Cochrane Library (including the Cochrane Database of Systematic Reviews, DARE and EMBASE), TRIP, Medline (1966-2006), Psych INFO (1960-2006), CINHAL (1982-2006) and BNI (1985-2006) were searched. The databases were searched using the relevant $\mathrm{MeSH}$ terms, including all subheadings, and this was combined with a keyword search. Search words included 'premenstrual syndrome', 'premenstrual tension', 'late luteal phase dysphoric disorder', 'premenstrual dysphoric disorder', 'PMDD', 'PMS', 'LLPDD' and 'PMT' and the search was limited to humans and the English language. The National Library for Health and the National Guidelines Clearing House were also searched for relevant guidelines and reviews. Enquiries for relevant information were also made to the pharmaceutical industry and researchers for missing studies and discussion with patient advocacy groups [e.g. the National Association for Premenstrual Syndrome (NAPS)]. A superscript system is also used (refer to Key on page 189) to indicate key facts for each intervention.

\section{Definition}

Many women experience mild physical and emotional PMS symptoms that are not particularly troublesome. However, when severe these symptoms can lead to a breakdown in interpersonal relationships and interfere with normal activities. A working definition of PMS is "a condition which manifests with distressing physical, behavioural and psychological symptoms not due to organic or underlying psychiatric disease, which regularly recurs during the luteal phase of each menstrual (ovarian) cycle and which disappears or significantly regresses by the end of menstruation". ${ }^{2}$ The severity of symptoms is

J Fam Plann Reprod Health Care 2009; 35(3): 187-194

(Accepted 31 May 2009)

Imperial College Healthcare NHS Trust and Chelsea and Westminster Hospitals, London, UK

Nick Panay, BSc, MRCOG, MFSRH, Senior Lecturer, Imperial College London; Chairman of National Association for Premenstrual Syndrome; Director of Menopause \& PMS Centre, Queen Charlotte's and Chelsea and Westminster Hospitals; Consultant Gynaecologist

Correspondence to: Mr Nick Panay, The Menopause and PMS Centre, Queen Charlotte's \& Chelsea Hospital, Du Cane Road, London W12 OHS, UK. E-mail: nickpanay@msn.com judged according to the degree of interference with day-today activities and relationships (Table 1). Premenstrual exaggeration or exacerbation of symptoms can also occur, though this is not regarded as the "core" diagnosis. Premenstrual dysphoric disorder (PMDD) is the American Psychiatric Association's definition of severe PMS in the Diagnostic and Statistics Manual - Version IV.

On a more global scale, the International Society for the Study of Premenstrual Disorders chaired by Professor PMS O'Brien has been working on reaching a consensus on a definition and management of premenstrual disorders. ${ }^{3}$ The aim is that the consensus document, currently under development, is eventually incorporated in the World Health Organization's new International Classification of Diseases (ICD-11).

\section{Aetiology}

The precise aetiology of PMS remains unknown but cyclical ovarian activity and the effect of estradiol and progesterone on the neurotransmitters serotonin and gamma-aminobutyric acid appear to be key factors. Absence of PMS before puberty, in pregnancy and after the menopause supports the theory that cyclical ovarian activity is important. Rapidly changing estradiol levels, not only premenstrually but also postnatally and perimenopausally, lead to this triad of hormone-dependent depressive disorders often in the same predisposed individual. ${ }^{4}$ Recent work has shown that the risk for PMDD is associated with a genetic variation in ESR1 [estrogen receptor (ER) alpha] gene. ${ }^{5}$ Haplotype analyses of ER alpha and beta were performed in 91 women with PMDD and 56 controls. Four single nucleotide polymorphisms (SNPs) of ESR1 showed significantly different genotype and allele distributions between patients and controls. However, the investigators pointed to the following limitations of the work thus far:

- The sample sizes were small therefore replication is required.

- Are there protective alleles in controls rather than susceptibility alleles in patients?

- The SNPs did not comprehensively interrogate the genes studied This may be the reason for the lack of association with ER beta.

- This is undoubtedly a complex genetic disorder. The degree of contribution of ER polymorphisms to the expression of PMDD is uncertain.

\section{Prevalence}

The reported prevalence of severe PMS is variable and between $3 \%$ and $30 \% .6,7$ The incidence of severe PMS or PMDD appears to be 5-8\%. PMS appears more prevalent in women who are obese, perform less exercise and are of lower academic achievement. There is a lower incidence of PMS in women using hormonal contraception.

\section{Diagnosis}

Crucial to the management of PMS is the need to make the correct diagnosis. This cannot be accurately established by retrospective recall. It needs to be made by the prospective logging of symptoms by the patient, ideally over two cycles. A symptom questionnaire that can be filled in online is available on the NAPS website (www.pms.org.uk). Alternatively, a well-established validated questionnaire 
[the Daily Record of Severity of Problems (DRSP); Figure 1$]^{8}$ can be used to document symptoms - this is particularly important if the patient is entered in a study. The questionnaires should continue to be filled in when treatment has been started to give an objective indication of response to therapy. Typical psychological symptoms include mood swings, irritability, depression and feeling out of control; physical symptoms include breast

\section{DAILY RECORD OF SEVERITY OF PROBLEMS \\ Please print and use as many sheets as you need for at Name or Initials least two FULL months of ratings.

Each evening note the degree to which you experienced each of the problems listed below. Put an " $x$ " in the box which corresponds to the severity: 1 - not at all, 2 - minimal, 3 - mild, 4 - moderate, 5 - severe, 6 - extreme.

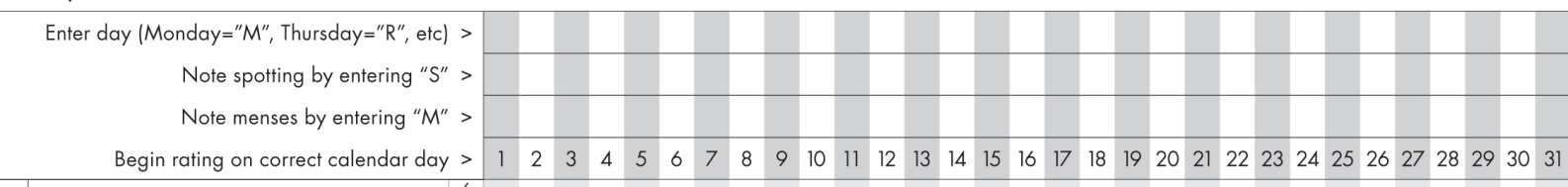

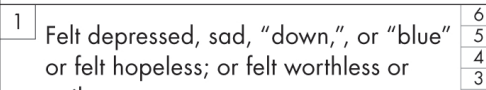
guilty

2 Felt anxious, tense, "keyed up" or "on edge"

3 Had mood swings (i.e., suddenly feeling sad or tearful) or was sensitive to rejection or feelings were easily hurt

4 Felt angry, or irritable

5 Had less interest in usual activities (work, school, friends, hobbies)

6 Had difficulty concentrating

7 Felt lethargic, tired, or fatigued; or had lack of energy

8 Had increased appetite or overate; or had cravings for specific foods

9 Slept more, took naps, found it hard to get up when intended; or had trouble getting to sleep or staying asleep

10 Felt overwhelmed or unable to cope; or felt out of control

11 Had breast tenderness, breast swelling, 6 bloated sensation, weight gain, headache, joint or muscle pain, or other physical symptoms

At work, school, home, or in daily routine, at least one of the problems noted above caused reduction of productivity or inefficiency

At least one of the problems noted above caused avoidance of or less participation in hobbies or social activities

At least one of the problems noted above interfered with relationships with others

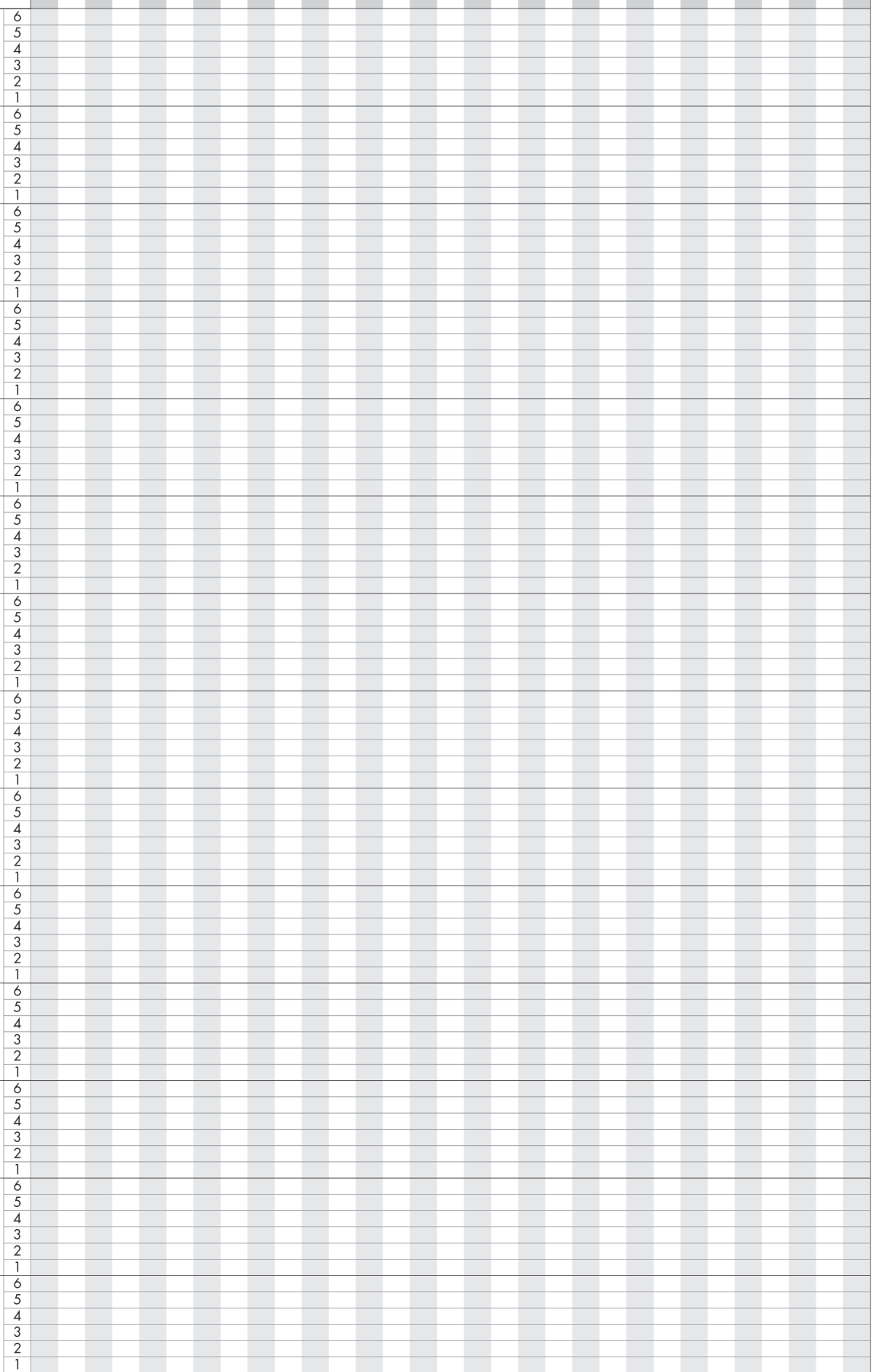

(C) Jean Endicott, PhD and Wilma Harrison, MD

Figure 1 The Daily Record of Severity of Problems (DRSP). 8 @ Jean Endicott and Wilma Harrison. Figure reproduced with the kind permission of the copyright holders 
Table 1 Definitions of the different types of premenstrual syndrome from Management of Premenstrual Syndrome. ${ }^{1}$ ( ) Royal College of Obstetricians and Gynaecologists

\begin{tabular}{ll}
\hline Type & Definition \\
\hline Premenstrual syndrome (PMS) & PMS symptoms leading up to menstruation and completely relieved by the end of menstruation. \\
Mild & Does not interfere with personal/social and professional life. \\
Moderate & $\begin{array}{l}\text { Interferes with personal/social and professional life but still able to function and interact, although } \\
\text { may be suboptimally. }\end{array}$ \\
Severe & $\begin{array}{l}\text { Unable to interact personally/socially/professionally - withdraws from social and professional activities } \\
\text { (treatment resistant). }\end{array}$ \\
Premenstrual exaggeration & $\begin{array}{l}\text { Background psychopathology, physical or other condition with incomplete relief of symptoms } \\
\text { when menstruation ends. }\end{array}$ \\
Premenstrual dysphoric disorder & $\begin{array}{l}\text { This is a research criterion, not in general use outside the USA. This definition of severe PMS has } \\
\text { been adopted by the American Psychiatric Association. }\end{array}$ \\
\hline
\end{tabular}

tenderness, bloating and headaches; behavioural symptoms include reduced visuo-spatial and cognitive ability and an increase in accidents. The psychological symptoms are usually complained of as being the most distressing to the sufferer, particularly their impact on relationships.

\section{Treatment}

\section{General principles of treatment}

When managing women with PMS, there are certain principles that should be adhered to. Even though not evidence-based, there is little doubt that reduction of stress for instance is a great help in ameliorating the symptoms. Also, dietary measures such as avoidance of carbohydrate binges and limitation of alcohol and caffeine intake are often of benefit. There are data from non-randomised trials suggesting that exercise improves PMS symptoms. ${ }^{9}$ However, in cases of moderate to severe PMS, it is important that medical therapy is instituted sooner rather than later to avoid unnecessary suffering. Women with marked underlying psychopathology as well as PMS should be referred to a psychiatrist. Symptom diaries (e.g. the DRSP) should be used to assess the effect of treatment.

\section{Service delivery}

Primary care should deal with most cases of PMS. Awareness of the condition and training in its management is essential. Ideally, women with severe PMS should be managed by a multidisciplinary team, which might comprise a hospital or community gynaecologist, psychiatrist or psychologist, dietician and counsellor. While such services are rarely provided in any National Health Service (NHS) setting, referral to gynaecologists should be reserved for women who have been fully evaluated as having severe PMS and when simpler forms of therapy have been explored. Where there is multidisciplinary provision of care, this is of benefit both from the diagnostic and therapeutic point of view, giving the ability to offer a broad range of interventions from lifestyle interventions and cognitive behavioural therapy (CBT) to gynaecological interventions. ${ }^{10}$

\section{Complementary therapies (CAMs)}

When treating women with PMS, complementary medicines may be of benefit, but clinicians need to consider that data from clinical studies are limited and underpowered. Interactions with conventional medicines should also be considered. The referring clinician retains legal responsibility for the patient's well being when they refer patients to complementary therapists. It is difficult to assess the true value of most of these therapeutic interventions because they are freely available without prescription or physician recommendation, with little regulation of efficacy or safety. Most are not licensed or registered for treatment of PMS. The Medicines and Healthcare products Regulatory Agency (MHRA) and European regulatory authorities are aiming to rectify the situation by insisting that all complementary therapies are registered by 2011 or withdrawn from sale. This section reviews the recent evidence for some of the evidence-based 'alternative' interventions that have been used to treat PMS. Treatments have been selected where reasonable efficacy data exist [randomised controlled trial (RCT) data if possible].

\section{Vitamin B6OTC IS}

Vitamin B6 is often used to treat PMS without clear evidence of its efficacy. ${ }^{11}$ The recommended dietary allowance for vitamin B6 is around $2.0 \mathrm{mg} / \mathrm{day}$ and deficiency of vitamin B6 is rare. Due to unproven efficacy of vitamin B6 in treating PMS, a systematic review of published and unpublished randomised placebo-controlled trials of effectiveness of vitamin B6 in the management of PMS was undertaken. ${ }^{12}$ Nine published trials representing 940 patients were reviewed. The main outcome measure was an improvement in overall premenstrual symptoms. The overall methodology of the trials identified was of poor quality, with none of the trials justifying patient numbers with a power calculation. The odds ratio (OR) in favour of vitamin $\mathrm{B} 6$ relative to placebo for an improvement in overall PMS was 2.32 (95\% CI 1.95-2.54). No conclusive evidence of vitamin B6 toxicity was reported and there was no dose-related response to treatment. There is no rationale for giving daily doses of vitamin B6 in excess of $100 \mathrm{mg}$, especially following the recommendation from the Department of Health and the Medicine Control Agency in 1999 to restrict the dose of vitamin B6 available generally to $10 \mathrm{mg}$ and to limit the dose sold by a pharmacist to less than $50 \mathrm{mg}$.

\section{Key to superscripts used in this review}

* Few treatments for PMS are actually licensed - the treatments with an asterisk are ones for which sufficient evidence exists for a general practitioner with an interest in women's health to reasonably prescribe from a medico-legal point of view.

HS Recommended for hospital specialist use.

IE Not recommended, insufficient evidence for efficacy.

IS Not recommended, insufficient evidence for safety.

OTC Over-the-counter medications. 


\begin{tabular}{|l|l|}
\hline First Line & $\begin{array}{l}\text { Exercise, cognitive behavioural therapy, vitamin B6 } \\
\text { Combined new-generation pill, such as Yasmin }{ }^{\circledR}, \text { Cilest }{ }^{\circledR} \text { (cyclically or continuously) } \\
\text { Continuous or luteal phase (Day 15-28) low-dose SSRIs }\end{array}$ \\
\hline Second Line & $\begin{array}{l}\text { Estradiol patches (100 } \mu \mathrm{g})+ \text { oral progestogen such as duphaston } 10 \text { mg (Day 17-28) or Mirena }{ }^{\circledR} \\
\text { Higher-dose SSRls continuously or luteal phase }\end{array}$ \\
\hline Third Line & GnRH analogues + add-back HRT (continuous combined estrogen + progestogen or tibolone) \\
\hline Fourth Line & Total abdominal hysterectomy and bilateral oophorectomy + HRT (including testosterone) \\
\hline
\end{tabular}

Figure 2 Algorithm for the management of severe premenstrual syndrome from Management of Premenstrual Syndrome. ${ }^{1} \odot$ Royal College of Obstetricians and Gynaecologists. GnRH, gonadotrophin-releasing hormone; HRT, hormone replacement therapy; SSRIs, selective serotonin reuptake inhibitors. Author's additional comments: (1) A newer alternative to Yasmin ${ }^{\circledR}$ is $\mathrm{Yaz}^{\circledR}$ (see text on page 191). (2) Utrogestan $200 \mathrm{mg}$ is an alternative to duphaston $10 \mathrm{mg}$.

\begin{abstract}
Magnesium OTC
Preliminary studies suggest that magnesium may also be helpful in PMS. A double-blind, placebo-controlled study of 32 women found that magnesium taken from Day 15 of the menstrual cycle to the onset of menstrual flow could significantly improve premenstrual mood changes. ${ }^{13}$ Another small, double-blind, preliminary study found that regular use of magnesium could reduce symptoms of PMSrelated fluid retention. ${ }^{14}$ In this study, 38 women were given magnesium or placebo for 2 months. One small, double-blind study (20 participants) found that magnesium supplementation with vitamin B6 might help prevent menstrual migraine. ${ }^{15}$
\end{abstract}

\section{Calcium/Vitamin DOTC}

Studies suggest that blood calcium and vitamin D levels are lower in women with PMS and that calcium supplementation may reduce symptom severity, but it is unknown whether this may prevent the initial development of PMS. In a recent case control study, after adjustment for risk factors, women in the highest quintile of total vitamin $\mathrm{D}$ intake (median, $706 \mathrm{IU} /$ day) had a relative risk of 0.59 (95\% CI 0.40-0.86) compared with those in the lowest quintile (median, $112 \mathrm{IU} /$ day) ( $p=0.01$ for trend). ${ }^{16}$ The intake of calcium from food sources was also inversely related to PMS; compared with women with a low intake (median, $529 \mathrm{mg} /$ day), participants with the highest intake (median, $1283 \mathrm{mg} /$ day) had a relative risk of $0.70(95 \% \mathrm{CI}$ $0.50-0.97)$ ( $p=0.02$ for trend). The intake of skimmed or low-fat milk was also associated with a lower risk $(p<0.001)$. A high intake of calcium and vitamin D may therefore reduce the risk of PMS but large-scale clinical trials addressing this issue are required. At present, the only interventional data are from small trials. ${ }^{17-19}$ More data are required to determine efficacy and to optimise regimens.

\section{Isoflavones (e.g. soy/red clover) OTC}

In a 24-week, double-blind study, 49 women with menstrual migraines received either placebo or a combination supplement containing soy isoflavones, dong quai and black cohosh extracts. The treatment group showed a significantly greater improvement than the placebo group. ${ }^{20}$ Recent data from the author's unit demonstrate a benefit with red clover isoflavones but this is not statistically significantly different to placebo. ${ }^{21}$ More data are required before a clear recommendation can be made for isoflavone usage.

\section{Agnus castus $\mathrm{OTC}$}

Agnus castus is the best researched CAM for PMS but a lack of standardised quality controlled preparations is a problem. The fruits of Vitex agnus castus (the chaste tree) contain a mixture of iridoids and flavonoids. The mechanism of action may be related to modulation of stress-induced prolactin secretion via dopamine, without directly affecting luteinising or follicle-stimulating hormones. A study was undertaken to compare the efficacy and tolerability of agnus castus with placebo in 170 women with PMS. Results showed improvement in the main variable was greater in the active group compared with placebo group. ${ }^{22}$ Patient acceptance was high and side effects were few and mild. A previous double-blind trial compared agnus castus to vitamin B6 (pyridoxine) instead of placebo. ${ }^{23}$ The two treatments proved equally effective. In a recently published study, 217 women were randomised. ${ }^{24}$ Efficacy was assessed using the Chinese version of the PMS diary (PMSD). The total PMSD score in the third cycle was highly significantly lower than the baseline in both groups $(p<0.0001)$. The difference in the mean scores from the baseline to the third cycle in the treatment group $(22.71 \pm 10.33)$ was significantly lower than the difference in the placebo group $(15.50 \pm 12.94$, $p<0.0001)$.

\section{St John's WortOTC}

Hypericum perforatum (St John's Wort) is a herbal remedy shown to alleviate mild to moderate depression. However, there has been no clinical investigation on its effectiveness in treating PMS apart from one case report and a small, prospective, open, uncontrolled, observational pilot study. ${ }^{25-26}$ The study investigated whether Hypericum could relieve PMS in a small group of women and tested the methods for conducting future RCTs with this 
preparation. Nineteen women with PMS used Hypericum tablets for two complete menstrual cycles. There were significant reductions in all outcome measures. The improvement was $51 \%$ when the PMS scores were measured between the baseline and the end of the trial, with over two-thirds of women demonstrating at least a $50 \%$ decrease in symptom severity. Symptoms which improved the most were emotional and cognitive, which correlates with evidence showing that Hypericum has positive effects on mood and that it may moderate brain neurotransmitters.

\section{Evening primrose oilOTC IE}

Evening primrose oil, a rich source of gamma linoleic acid, is often used as a treatment for severe PMS. However, the evidence for efficacy in this condition is poor. A prospective, randomised, double-blind and placebo-controlled trial showed that there was no significant difference in the scoring between the active and placebo groups over six cycles. These findings indicate that the improvement experienced by these women with moderate PMS was solely a placebo effect. ${ }^{27}$ A metaanalysis of the data has also concluded that evening primrose oil is ineffective in the treatment of severe PMS. 28 Only cyclical mastalgia has been shown to respond to this treatment. ${ }^{29}$

\section{Medical treatment of PMS}

A suggested treatment algorithm as proposed in the RCOG Green-top Guideline ${ }^{1}$ for PMS is shown in Figure 2. Most efficacious treatments for PMS are unlicensed. However, in this situation unlicensed treatments can be justified where a body of evidence and safety exist. The two chief evidence-based medical treatments of moderate to severe PMS are categorised by ovulation suppression and selective serotonin reuptake inhibitors (SSRIs).

\section{Ovarian suppression}

Although the underlying cause of severe PMS remains unknown, cyclical ovarian activity appears to be an important factor. A logical treatment for severe PMS, therefore, is to suppress ovulation and thus suppress the cyclical endocrine/biochemical changes that cause the distressing symptoms. A number of drugs are capable of performing this function, but they are not without their own side effects, which may influence the efficacy of the treatment or the duration for which they may be given.

\section{Combined oral contraceptive pill*}

Although able to suppress ovulation, and used commonly to improve PMS symptoms, the combined pill was initially not shown to be of benefit in randomised prospective trials. ${ }^{30}$ This is probably because it was used with a pillfree week and because the daily progestogen in the second generation pills (e.g. levonorgestrel) regenerated PMS-type symptoms. The relatively new combined oral contraceptive pill (COC) $\left(\right.$ Yasmin $\left.{ }^{\circledR}\right)$ containing an anti-mineralocorticoid and anti-androgenic progestogen, drospirenone, showed considerable promise in the treatment of severe PMS as it minimised progestogenic side effects with a mild diuretic and anti-androgenic effect. Both observational and small randomised trial data supported efficacy. ${ }^{31}$ However, the development of Yasmin has now been succeeded by Yaz $^{\circledR}$, a $20 \mu \mathrm{g}$ ethinylestradiol $/ 3 \mathrm{mg}$ drospirenone COC but in a $24 / 4$ rather than the conventional $21 / 7$ regimen. The reduction of the hormone-free interval to 4 days reduces the risk of cycle-related symptoms. Two randomised prospective studies trials have demonstrated the efficacy of Yaz over placebo in the treatment of PMDD. 32,33
If the "conventional" $21 / 7$ regimen COC is used to treat severe PMS, pill packets should be used back to back (bicycling/tricycling) to avoid the regeneration of cyclerelated symptoms during the hormone-free interval. ${ }^{34}$ There are data supporting the continuous use of the COC with a break only introduced if breakthrough bleeding occurs. ${ }^{35}$

\section{Transdermal estradiol*}

Oral preparations give insufficient estradiol levels to suppress ovarian activity. A placebo-controlled trial demonstrated that implanted $17 \beta$-estradiol combined with cyclical progestogen was effective for the management of physical and psychological symptoms of severe PMS. Administered as a $100 \mathrm{mg}$ implant, this proved to be highly effective when compared with placebo. ${ }^{36}$ Implants are less commonly used for PMS since patches have become available, due to their long-lasting effects.

In a randomised, double-blind, placebo-controlled trial of 20 women with crossover at 3 months, transdermal estradiol patches $(200 \mu \mathrm{g})$ were assessed and found to be highly effective. 37 Women in the active treatment group received two $100 \mu \mathrm{g}$ estradiol patches followed by placebo and 20 women were treated in reverse order. Significant improvements occurred after changing to active treatment in five of six negative MDQ (Menstrual Distress Questionnaire) symptom clusters and in six of ten PDQ (Premenstrual Distress Questionnaire) symptoms. There was concern that estradiol $200 \mu \mathrm{g}$ twice weekly was still too high a dose to be used as long-term therapy. A subsequent randomised study 38 showed that $100 \mu \mathrm{g}$ estradiol patches twice weekly were as effective as $200 \mu \mathrm{g}$ in reducing symptom levels in severe PMS and this dosage was better tolerated. A recently concluded study from the author's unit has shown similar benefits of $100 \mu \mathrm{g}$ patches over placebo with benefits lasting up to 14 months. ${ }^{39}$

Additional barrier or intrauterine methods of contraception should be used when estradiol (patches and implant) are used in PMS as ovulation suppression cannot be guaranteed. There are insufficient data to confirm longterm endometrial and breast safety because long-term randomised prospective safety studies are lacking. However, logic dictates that the hormonal environment is not significantly different to how it would otherwise be in this premenopausal population and observation has not shown any problems over 20 years of usage.

\section{Progestogen intolerance}

Use of continuous estradiol normally necessitates the addition of cyclical progestogen (10-12 days) to avoid endometrial hyperplasia in women who have a uterus. A study of long-term treatment with the $100 \mu \mathrm{g}$ dosage using a low dose of cyclical norethisterone acetate (NETA) [1 mg; 10 days/cycle] has shown benefit over placebo over eight cycles with continued improvement in a 6-month extension. ${ }^{39}$ Intrauterine administration of progestogen has the potential to avoid systemic absorption and hence avoid progestogenic effects. The levonorgestrel-releasing intrauterine system (LNG-IUS) as progestogen replacement can maximise efficacy by minimising PMSlike adverse effects. Low systemic levels of levonorgestrel released by the LNG-IUS can initially produce PMS-type adverse effects (as well as bleeding) in the progestogenintolerant woman. Despite this, it might still be of advantage to use a LNG-IUS or vaginal progesterone (cyclogest pessaries or crinone gel $8 \%$ - not licensed for this indication in this age group) in the progestogenintolerant woman. ${ }^{40}$ In general, when treating women with PMS, treatment with the lowest possible dose of progestogen is recommended to minimise adverse effects. 


\section{DanazolHS}

Cycle suppression may be achieved using danazol, an androgenic steroid. Studies have demonstrated benefit for several symptoms, ${ }^{41,42}$ but due to masculinising sideeffects, especially at higher, cycle-suppressing doses, it is not commonly used.

\section{Gonadotrophin-releasing hormone (GnRH) analogues ${ }^{\mathrm{HS}}$}

Gonadotrophin-releasing hormone $(\mathrm{GnRH})$ analogues have been very successfully employed for many years to suppress ovarian steroid production. ${ }^{43-46}$ Early resort to GnRH therapy for PMS is not recommended due to the potential side effects and cost. Prolonged use should be retained for women with the most severe symptoms. A recent meta-analysis of $\mathrm{GnRH}$ analogues has confirmed their efficacy compared with placebo. ${ }^{43}$ Seventy-one women on active treatment were identified in seven trials. The overall standardised mean difference (SMD) for all trials was -1.19 (95\% CI -1.88 to -0.51 ) (Cohen criteria: 0.3 small, 0.5 medium, 1.0 large effect) The OR for benefit was 8.66 (95\% CI $2.52-30.26)$. The SMD was -1.43 and OR 13.38 (95\% CI 3.9-46.0) if data were taken only from anovulation trials. Efficacy of symptom relief was greater for physical than for behavioural symptoms: physical SMD -1.16 (95\% CI -1.53 to -0.79 ); behavioural SMD -0.68 (95\% CI -1.11 to -0.25$)$ but the difference was not significant $(p=0.484)$.

Data show that symptoms due to the hypo-estrogenic state can be virtually eliminated and bone mineral density can be maintained by the use of hormone replacement therapy (HRT). Continuous combined therapy or tibolone is preferable to sequential combined therapy in order to minimise the risks of symptom reappearance of PMS-like progestogenic effects. 44,45 Overall SMD favoured neither GnRH alone or GnRH with add back (95\% CI -0.34 to 0.59 ) demonstrating there is no reversal of the beneficial effect of GnRH when using add-back. ${ }^{46}$

When treating women with PMS with GnRH analogue therapy, treatment should only be continued for 6 months when used alone. Treatment should be combined with HRT to reduce trabecular bone density loss. Women on longterm treatment should have annual measurement of bone mineral density (BMD) (ideally by dual-energy X-ray absorptiometry). Treatment should be stopped if BMD declines significantly in scans performed 1 year apart. General advice about how exercise, diet and smoking affect BMD should be given.

\section{Progesterone $\mathrm{IE} /$ progestogens $\mathrm{IE}$}

A recent meta-analysis of all published studies for progestogen and progesterone treatment of PMS demonstrated no benefit for treatment. ${ }^{47}$ The objective of this systematic review was to evaluate the efficacy of progesterone and progestogens in the management of PMS. Ten trials of progesterone therapy (531 women) and four trials of progestogen therapy ( 378 women) were reviewed. The main outcome measure was a reduction in overall symptoms of PMS. All the trials of progesterone (by both routes of administration) showed no clinically significant difference between progesterone and placebo. For progestogens, the overall SMD for reduction in symptoms showed a slight non-significant difference in favour of progestogen, with the mean difference being $-0.036(95 \%$ CI -0.059 to -0.014$)$. The meta-analysis of this systematic review suggested that there was no published evidence to support the use of either exogenous progesterone or progestogens in the management of PMS.
The findings of this study were not entirely surprising. Synthetic progestogens actually have PMS-like side effects! Natural progesterone could have some benefits as it can have an anxiolytic effect and act as a mild diuretic. However, of the few underpowered studies conducted only one has shown benefit and better data are needed. 48

Depot medroxyprogesterone acetate (Depo-Provera ${ }^{\circledR}$ ), etonorgestrel rods (Implanon ${ }^{\circledR}$ ) and the ovulationsuppressing progestogen-only pill (Cerazette ${ }^{\circledR}$ ) all have ovulation suppressant activity. However, cyclical symptoms can be replaced by continuous low-grade symptoms due to the PMS-like side effects of synthetic progestogens. Data regarding efficacy are therefore either absent or at best contradictory.

\section{HysterectomyHS}

Total abdominal hysterectomy and bilateral salpingooophorectomy is the ultimate form of ovulation suppression and the only true cure for PMS as this removes the ovarian cycle completely. The procedure is only rarely performed for this indication, as a lesser alternative can usually be found. When treating women with PMS, surgery should not be contemplated without preoperative use of $\mathrm{GnRH}$ analogues as a test of cure and to ensure that HRT is tolerated. Such therapy should be reserved for extremely severe PMS sufferers in whom other treatments have failed. When appropriately targeted, this intervention can have life-altering benefits. 49

It is essential that adequate hormone therapy is given (including consideration of testosterone replacement) to prevent simply replacing one set of symptoms with another. Women who have had a hysterectomy with ovarian conservation will often continue to have cyclical symptoms in the absence of menstruation.

\section{Selective serotonin reuptake inhibitors (SSRIs)*}

There is increasing evidence that serotonin may be important in the pathogenesis of PMS. A number of selective serotonin reuptake inhibitors (SSRIs) have been used to treat severe PMS/PMDD. One study consisted of two phases with an initial single-blind washout period followed by a randomised, double-blind, placebo-controlled trial lasting six menstrual cycles. Fluoxetine at 20 or $60 \mathrm{mg}$ was found to significantly reduce symptoms of tension, irritability and dysphoria, as well as physical symptoms compared with placebo, as measured by visual analogue scales $(p<0.001) .50$ The mean percentage improvement in the luteal phase score from baseline was four to six times greater in the fluoxetine groups than in the placebo group. The adverse effects reported during the trial were dose related, with significantly fewer events occurring in the placebo group and the group receiving $20 \mathrm{mg}$ fluoxetine/day than in the group given $60 \mathrm{mg}$ fluoxetine/day $(p<0.001)$. There are also data suggesting improvement of physical symptoms with SSRIs, though this is probably due to the improved perception rather than genuine reduction in symptom severity. ${ }^{51}$ A meta-analysis of all available RCTs involving SSRIs used in PMS confirmed superior efficacy compared with placebo. 52

The Commission on Human Medicines endorses the view that SSRIs are effective medicines in the treatment of depression and anxiety conditions and that the balance of risks and benefits in adults remains positive in their licensed indications. Prescribing should be restricted to those health professionals who have a particular expertise in this area.

There now exists a wealth of data from other RCTs for the treatment of severe PMS with most types of SSRIs. Randomised studies have now shown that half-cycle SSRI 
treatment is as efficacious as continuous administration. A randomised, double-blind study compared the responses to luteal phase or full-cycle dosing of sertraline in 31 women fulfilling criteria for severe PMS who completed a preceding double-blind, short-term treatment trial that lasted three menstrual cycles. The results showed that the total PMS scores were lower in the luteal-phase dosing group in each of the three treatment months but the differences were not statistically significant from full-cycle dosing group. Further analysis of each of the symptoms showed significant differences $(p<0.05)$ in favour of lutealphase dosing for mood swings, nervous tension, feeling out of control and confusion. ${ }^{53}$ There are also data to suggest that luteal-phase dosing improves symptoms that continue into the post-menstrual phase. ${ }^{54}$

The importance of this is that patients are less likely to develop dependence on this regimen, benefit is immediate and patients are more likely to accept the treatment as it can be regarded as being different to the regimens used for psychiatric disorders. In the author's opinion, the optimum regimens for PMS are half-cycle citalopram or escitalopram, $20 \mathrm{mg}$ per day from Day 15 to Day 28 of the cycle. This regimen appears to be effective even in women whose previous SSRI treatment has failed.55 Severe PMS also improves significantly with either luteal-phase or symptom-onset dosing of escitalopram with good tolerability. ${ }^{56}$ SSRIs/SNRIs (serotoninnorepinephrine reuptake inhibitors) should be considered one of the first-line pharmaceutical management options in severe PMS.

\section{Cognitive behavioural therapy (CBT)}

A recent study examined the relative effectiveness of fluoxetine (20 mg daily) and CBT (10 sessions), and combined therapy (fluoxetine plus CBT) in women with PMDD. 57 This was a randomised treatment trial lasting 6 months; follow-up was undertaken 1 year post-treatment. Significant improvement occurred in all three treatment groups after 6 months of treatment. Fluoxetine was associated with a more rapid improvement but, at followup, CBT was associated with better maintenance of treatment effects compared with fluoxetine. There appeared to be no additional benefit of combining the treatments and no difference in efficacy between the treatment groups. A clinical psychology service should be available for women with PMS, ideally as part of the multidisciplinary team.

\section{Conclusions}

PMS continues to be poorly understood and in many cases inadequately managed. It can be the cause of considerable morbidity and at times even mortality. It is imperative that a consensus on definition is reached globally and that properly conducted research continues to be funded. It is only through this work that clinicians will be able to practise in a truly evidence-based way to effectively treat this condition.

The alternatives to traditional therapy, such as agnus castus, red clover and St John's Wort, are showing promising results in RCTs but more data are needed. The data on natural progesterone remain controversial, although many women appear to derive considerable benefit from being on this preparation. Progestogens should not be used as they are very good at reproducing the symptoms of PMS. The more established therapies for which RCT data exist are the newer combined pills (especially Yaz) containing progestogens other than norethisterone and levonorgestrel, transdermal oestradiol, SSRIs and the GnRH analogues. ${ }^{58,59}$ Hysterectomy with bilateral salpingo-oophorectomy and adequate HRT remains an option for the severely afflicted woman whose family is complete and who has not responded fully to the other therapies.

\section{Statements on funding and competing interests}

Funding None identified.

Competing interests The author has received honoraria for speaking and advising a number of pharmaceutical companies whose products are mentioned in this review and has also conducted sponsored research with some of these products.

\section{References}

1 Royal College of Obstetricians and Gynaecologists (RCOG). Management of Premenstrual Syndrome (Green-top Guideline No. 48), Panay N (ed.). December 2007. http://www.rcog. org.uk/files/rcog-corp/uploaded-files/GT48Management PremensturalSyndrome.pdf [Accessed 10 May 2009].

2 Magos AL, Studd JWW. The premenstrual syndrome. In: Studd $\mathrm{J}$ (ed.), Progress in Obstetrics and Gynaecology (Vol. 4). London, UK: Churchill Livingstone, 1984; 334-350.

3 Halbreich U, Backstrom T, Eriksson E, O'Brien S, Calil H, Ceskova $\mathrm{E}$, et al. Clinical diagnostic criteria for premenstrual syndrome and guidelines for their quantification for research studies. Gynecol Endocrinol 2007; 23: 123-130.

4 Panay N, Studd JWW. The psychotherapeutic effects of estrogens. Gynecol Endocrinol 1998; 12: 353-365.

5 Huo L, Straub RE, Roca C, Schmidt PJ, Shi K, Vakkalanka R, et al. Risk for premenstrual dysphoric disorder is associated with genetic variation in ESR1, the estrogen receptor alpha gene. Biol Psychiatry 2007; 62: 925-933.

6 Reid RL. Premenstrual syndrome. N Eng J Med 1991; 324: 1208-1210.

7 Sadler C, Inskip H, Smith H, Panay N. A study to investigate the relationship between lifestyle factors and premenstrual symptoms. Menopause Int 2004; 10(Suppl. 2): 15.

8 Endicott J, Nee J, Harrison W. Daily Record of Severity of Problems (DRSP): reliability and validity. Arch Womens Ment Health 2006; 9: 41-49.

9 Prior JC, Vigna Y, Sciarretta D, Alojado N, Schulzer M. Conditioning exercise decreases premenstrual symptoms: a prospective, controlled 6-month trial. Fertil Steril 1987; 47: 402-408.

10 Girman A, Lee R, Kligler B. An integrative medicine approach to premenstrual syndrome. Am J Obstet Gynecol 2003; 188 (5 Suppl.): S56-S65.

11 Kleijnen J, Ter Riet G, Knipschild P. Vitamin B6 in the treatment of premenstrual syndrome - a review. $\mathrm{Br} J$ Obstet Gynaecol 1990; 97: 847-852.

12 Wyatt K, Dimmock P, Jones P, O'Brien P. Efficacy of vitamin B-6 in the treatment of premenstrual syndrome: systematic review. BMJ 1999; 318: 1375-1381.

13 Facchinetti F, Borella P, Sances G, Fioroni L, Nappi RE, Genazzani AR. Oral magnesium successfully relieves premenstrual mood changes. Obstet Gynecol 1991; 78: 177-181.

14 Walker AF, De Souza MC, Vickers MF, Abeyasekera S, Collins $\mathrm{ML}$, Trinca LA. Magnesium supplementation alleviates premenstrual symptoms of fluid retention. J Womens Health 1998; 7: 1157-1165.

15 De Souza MC, Walker AF, Robinson PA, Bolland K. A synergistic effect of a daily supplement for 1 month of $200 \mathrm{mg}$ magnesium plus $50 \mathrm{mg}$ vitamin B6 for the relief of anxietyrelated premenstrual symptoms: a randomized, double-blind, crossover study. J Womens Health Gend Based Med 2000; 9: 131-139.

16 Bertone-Johnson ER, Hankinson SE, Bendich A, Johnson SR, Willett WC, Manson JE. Calcium and vitamin D intake and risk of incident premenstrual syndrome. Arch Intern Med 2005; 165: 1246-1252.

17 Alvir JM, Thys-Jacobs S. Premenstrual and menstrual symptom clusters and response to calcium treatment. Psychopharmacol Bull 1991; 27: 145-148.

18 Thys-Jacobs S, Ceccarelli S, Bierman A, Weisman H, Cohen MA, Alvir J. Calcium supplementation in premenstrual syndrome: a randomized crossover trial. J Gen Intern Med 1989; 4: 183-189.

19 Thys-Jacobs S, Starkey P, Bernstein D, Tian J. Calcium carbonate and the premenstrual syndrome: effects on premenstrual and menstrual symptoms. Premenstrual Syndrome Study Group. Am J Obstet Gynecol 1998; 179: 444-452.

20 Burke BE, Olson RD, Cusack BJ. Randomized, controlled trial of phytoestrogen in the prophylactic treatment of menstrual 
migraine. Biomed Pharm 2002; 56: 283-288.

21 Taher S, Cahill A, Eliahoo J, Calvin M, Rothon C, Panay N Randomised placebo controlled pilot study comparing red clover (P-07) versus placebo for the treatment of premenstrual syndrome. Maturitas 2009; 63: S114-S115.

22 Schellenberg R. Treatment for the premenstrual syndrome with agnus castus fruit extract: prospective, randomised, placebocontrolled study. BMJ 2001; 322: 134-137.

23 Lauritzen C, Reuter HD, Repges R, et al. Treatment of premenstrual tension syndrome with Vitex agnus castus. Controlled, double-blind study versus pyridoxine. Phytomedicine 1997; 4: 183-189.

$24 \mathrm{He} \mathrm{Z}$, Chen R, Zhou Y, Geng L, Zhang Z, Chen S, et al. Treatment for premenstrual syndrome with Vitex agnus castus: a prospective, randomized, multi-center placebo controlled study in China. Maturitas 2009; 6 March [Epub ahead of print].

25 Stevinson C, Ernst E. A pilot study of Hypericum perforatum (St John's Wort) for the treatment of premenstrual syndrome. Br J Obstet Gynaecol 2000; 107: 870-876.

26 Huang KL, Tsai SJ. St. John's wort (Hypericum perforatum) as a treatment for premenstrual dysphoric disorder: case report. Int J Psychiatry Med 2003; 33: 295-297.

27 Khoo SK, Munro C, Battistutta D. Evening primrose oil and treatment of premenstrual syndrome. Med J Aust 1990; 153: 189-192.

28 Budieri D, Li-Wan Po A, Dornan JC. Is evening primrose oil of value in the treatment of premenstrual syndrome? Control Clin Trials 1996; 17: 60-68.

29 Cheung KL. Management of cyclical mastalgia in oriental women: pioneer experience of using gamolenic acid (Efamast) in Asia. Aust N Z J Surg 1999; 69: 492-494.

30 Graham CA, Sherwin BB. A prospective treatment study of premenstrual symptoms using a triphasic oral contraceptive. $J$ Psychosom Res 1992; 36: 257-266.

31 Freeman EW, Kroll R, Rapkin A, Pearlstein T, Brown C, Parsey $\mathrm{K}$, et al.; PMS/PMDD Research Group. Evaluation of a unique oral contraceptive in the treatment of premenstrual dysphoric disorder. J Womens Health Gend Based Med 2001; 10: 561-569.

32 Pearlstein TB, Bachmann GA, Zacur HA, Yonkers KA Treatment of premenstrual dysphoric disorder with a new drospirenone-containing oral contraceptive formulation. Contraception 2005; 72: 414-421.

33 Yonkers KA, Brown C, Pearlstein TB, Foegh M, SampsonLanders C, Rapkin A. Efficacy of a new low-dose oral contraceptive with drospirenone in premenstrual dysphoric disorder. Obstet Gynecol 2005; 106: 492-501.

34 Sulak PJ, Scow RD, Preece C, Riggs MW, Kuehl TJ. Hormone withdrawal symptoms in oral contraceptive users. Obstet Gynecol 2000; 95: 261-266.

35 Coffee AL, Kuehl TJ, Willis S, Sulak PJ. Oral contraceptives and premenstrual symptoms: comparison of a 21/7 and extended regimen. Am J Obstet Gynecol 2006; 195: 1311-1319.

36 Magos AL, Brincat M, Studd J. Treatment of the premenstrual syndrome by subcutaneous oestradiol implants and cyclical oral norethisterone: placebo controlled study. BMJ 1986; 292: $1629-1633$.

37 Watson NR, Studd JWW, Savvas M, Garnett T, Baber RJ. Treatment of severe premenstrual syndrome with oestradiol patches and cyclical oral norethisterone. Lancet 1989, 2(8665): 730-732.

38 Smith RNJ, Studd JWW, Zamblera D, Holland EF. A randomised comparison over 8 months of $100 \mathrm{mg}$ and $200 \mathrm{mg}$ twice weekly doses of transdermal oestradiol in the treatment of severe premenstrual syndrome. Br J Obstet Gynaecol 1995; 102: 475-484.

39 Panay N, Studd J. The management of PMDD through ovarian cycle suppression. In: S O'Brien S, Rapkin AJ, Schmidt PJ (eds), Premenstrual Syndromes: PMS and PMDD. London, UK: Informa Healthcare, 2007; 121-130.

40 Panay N, Studd J. Progestogen intolerance and compliance with hormone replacement therapy in menopausal women. Hum Reprod Update 1997; 3: 159-171.

41 Watts JF, Butt WR, Logan Edwards R. A clinical trial using danazol for the treatment of premenstrual tension. $\mathrm{Br} J$ Obstet Gynaecol 1987; 94: 30-34.
42 Hahn PM, Van Vugt DA, Reid RL. A randomised, placebocontrolled, crossover trial of danazol for the treatment of premenstrual syndrome. Psychoneuroendocrinology 1995, 20: 193-209.

43 Wyatt KM, Dimmock PW, Ismail KM, Jones PW, O'Brien PM. The effectiveness of GnRHa with and without 'add-back' therapy in treating premenstrual syndrome: a meta analysis. $\mathrm{Br}$ J Obstet Gynaecol 2004: 111: 585-593.

44 Leather AT, Studd JWW, Watson NR, Holland EF. The prevention of bone loss in young women treated with $\mathrm{GnRH}$ analogues with add-back estrogen therapy. Obstet Gynecol 1993; 81: 104-107.

45 Di Carlo C, Palomba S, Tommaselli GA, Guida M, Di Spiezio Sardo A, Nappi C. Use of leuprolide acetate plus tibolone in the treatment of severe premenstrual syndrome. Fertil Steril 2001; 75: $380-384$.

46 Sagsveen M, Farmer J, Prentice A, Breeze A. Gonadotrophinreleasing analogues for endometriosis: bone mineral density. Cochrane Database Syst Rev 2003; (4): CD001297.

47 Wyatt K, Dimmock P, Jones P, Obhrai M, O'Brien S. Efficacy of progesterone and progestogens in management of premenstrual syndrome: systematic review. BMJ 2001; 323: $1-8$.

48 Magill PJ, Progesterone Study Group. Investigation of the efficacy of progesterone pessaries in the relief of symptoms of premenstrual syndrome. Br J Gen Pract 1995: 45: 589-593.

49 Cronje WH, Vashisht A, Studd JW. Hysterectomy and bilateral oophorectomy for severe premenstrual syndrome. Hum Reprod 2005; 19: 2152-2155.

50 Steiner M, Steinberg S, Stewart D, Carter D, Berger C, Reid R, Grover D, Streiner D. Fluoxetine in the treatment of premenstrual dysphoria. NEJM 1995;23:1529-1534.

51 Steiner M, Romano SJ, Babcock S, Dillon J, Shuler C, Berger $\mathrm{C}$, et al. The efficacy of fluoxetine in improving physical symptoms associated with premenstrual dysphoric disorder. $\mathrm{Br}$ $J$ Obstet Gynecol 2001; 108: 462-468.

52 Dimmock PW, Wyatt KM, Jones PW, O'Brien PM. Efficacy of selective serotonin-reuptake inhibitors in premenstrual syndrome: a systematic review. Lancet 2000; 356(9236): 1131-1136.

53 Freeman E, Rickels K, Arredondo F, Kao LC, Pollack S, Sondheimer S. Full or half-cycle treatment of severe premenstrual syndrome with a serotonergic antidepressant. J Clin Psychopharmacol 1999; 19: 3-8

54 Yonkers K, Pearlstein T, Fayyad R, Gillespie J. Luteal phase treatment of premenstrual dysphoric disorder improves symptoms that continue into the postmenstrual phase. J Affect Disord 2005; 85: 317-321.

55 Freeman EW, Jabara S, Sondheimer SJ, Auletto R. Citalopram in PMS patients with prior SSRI treatment failure: a preliminary study. J Womens Health Gend Based Med 2002; 11: 459-464.

56 Freeman EW, Sondheimer SJ, Sammel MD, Ferdousi T, Lin H. A preliminary study of luteal phase versus symptom-onset dosing with escitalopram for PMDD. J Clin Psychiatry 2005; 66: 769-773.

57 Hunter MS, Ussher JM, Browne SJ, Cariss M, Jelley R, Katz M. A randomized comparison of psychological (cognitive behaviour therapy), medical (fluoxetine) and combined treatment for women with premenstrual dysphoric disorder. J Psychosom Obstet Gynaecol 2002; 23: 193-199.

58 Yonkers KA, O'Brien PM, Eriksson E. Premenstrual syndrome. Lancet 2008; 371(9619): 1200-1210.

59 Panay N. Understanding the pain: managing severe PMS. Pract Midwife 2008; 11: 26-29.

Further reading/information

$1 \mathrm{Ng} \mathrm{C}$, Cloke B, Panay N. Management of severe premenstrual syndrome. In: Barter J, Hampton N (eds), The Year in Obstetrics \& Gynaecology. Oxford, UK: Clinical Publishing Services, 2002; Part III, 181-196.

2 O'Brien S, Rapkin AJ, Schmidt PJ (eds). Premenstrual Syndromes: PMS and PMDD. London, UK: Informa Healthcare, 2007.

3 National Association for Premenstrual Syndrome (NAPS). Advice for sufferers and health professionals. Website: www.pms.org.uk.

\section{Visit the Faculty Website at www.fsrh.org}

